\title{
Optimization of Gasoline Engine to Maximize Brake Power and Minimize Brake Specific Fuel Consumption with Artificial Neural Network and Killer Whale Algorithm
}

\author{
Totok R. Biyanto*, Muhammad F. Auliya, Ronny D. Noriyati, Hendra Cordova, Martadji, Hafisyah R. \\ Putra \\ Department of Engineering Physics, Institut Teknologi Sepuluh Nopember, Surabaya, Indonesia
}

\begin{abstract}
In Formula Society of Automotive Engineering (SAE) competition, the design of efficient and powerful combustion engine is required. This paper discussed optimization of gasoline engine using Killer Whale algorithm. The modelling of gasoline engine was built using Multi-Layer Perceptron - Artificial Neural Network (MLP-ANN). A gasoline engine was simulated using Ricardo Wave commercial software to acquire data for training and testing the proposed ANN. The ANN weights were determined by utilizing Levenberg-Marquardt algorithm. The objective function in this paper is to maximize power, minimize the Brake Specific Fuel Consumption (BSFC) and minimize the operational cost. The optimized variables are engine speed (rpm), Air Fuel Ratio (AFR), Mass Fuel Flow (MFF), Intake Pressure (IP), Intake Air Temperature (IAT), Combustion Start (CS) and Throttle Angle (TA). Root Mean Square Error (RMSE) of ANN modelling is $0.021 \mathrm{~kW}$ for power and $0.00032 \mathrm{~kg} / \mathrm{kW}$.hr for BSFC. The optimization results show that the power increases to $13 \%$, BSFC decreases to $11 \%$ and the cost operation decreases to $23 \%$ compare with existing design variables.
\end{abstract}

Keywords: ANN; BSFC; optimization; power.

\section{INTRODUCTION}

Power and efficiency of spark ignition engines are influenced by many variables and parameters. The correlation among them are very complex and nonlinear [1]. Hence, the model that have capability to capture the complexity and nonlinearity of the system is required, such as Artificial Neural Network (ANN).

Artificial neural network (ANN) models have been widely used in several engineering practices due to their abilities to map highly nonlinear relationships. This ability makes ANNs appropriate to solve complex and nonlinear problems. A study of engine calibration has been investigated by utilizing ANN model to minimize carbon monoxide (CO) and carbon dioxide (CO2) in flue gas engine [2]. A multilayer perceptron (MLP) ANN is used to model the brake power, output torque, specific fuel consumption, and exhaust emissions of a diesel engine [3]. Another application of ANN model to predict the performance and exhaust emissions of a diesel engine including $\mathrm{CO}, \mathrm{NO} x$ and unburned hydrocarbons has been investigated [4]. Moreover, the modeling of gasoline engine using neural network has been performing to predict brake power with engine speed, engine torque, fuel flow rate, intake manifold mean temperature and cooling water inlet temperature as regressor [5]. The latest reference regarding optimization of gasoline engine using ANN and stochastic optimization such as genetic algorithm has been described in the literature [6]. Engine speed, Angle of throttle valve, injected fuel flow, injection time, ignition timing was utilized as optimized variables to minimize the concentration of $\mathrm{CO}$ $\mathrm{HC}$ and NOx in flue gas engine [7].
In this paper, utilizing an ANN to predict power and fuel consumption with input engine speed (RPM), air fuel ratio (AFR), mass fuel flow (MF), intake pressure (IP), intake air temperature (IAT), combustion start (CS) and throttle angle (TA) as optimized variable was performed by Killer Whale Algorithm (KWA).

\section{LITERATURE REVIEW}

The ANN is a system easily modeled on the human brain. ANNS are popular and there are many industrial situations where they can be usefully applied. They are suitable for modelling various manufacturing functions due to their ability to learn complex non-linear and multivariable relationships between process parameters. A neural network system has three layers, namely the input layer, the hidden layer and the output layer. The input layer consists of all the input factors, information from the input layer is then processed in the course of one hidden layer, and following output vector is computed in the output layer. The estimation problem using neural network models has three successive steps: model building or neural network architecture; the learning or training procedure; and the testing procedure. An important stage when accommodating a neural network is the training step, in which an input is introduced to the network together with the desired outputs, the weights and bias values are initially chosen randomly and the weights are adjusted so that the network attempts to produce the desired output. Many alternative training processes, such as back-propagation, are available. The goal of any training algorithm is to minimize the global error level, such as the mean \% error, root-meansquared (RMS), and absolute fraction of variance (R2) [8]. 
Killer Whales (Orcinus Orca) is the marine mammals that are on the highest peak of the food chain in marine ecological system, or in other words is the Apex Marine Predator. According to [9], in order to examine the use of echolocation by Killer Whale, a mathematical model that represents Killer Whales in foraging of prey, this mathematical model were used as a search agents movement to find best solution from an objective function [9].

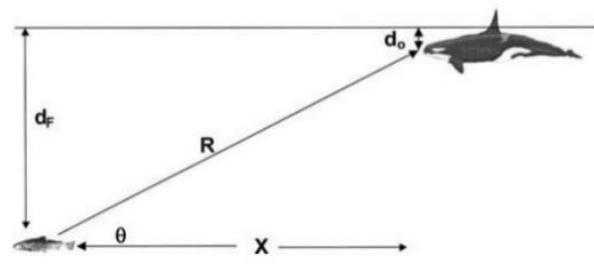

Fig. 1. Foraging Geometry showing a Killer Whale at depth $d_{o}$ in pursuit of a Prey at range $R$ and a depth $d_{F}$ [9].

The following notations are used in Fig. 1: $d_{F}$ and $d_{o}$ are the depth of the prey and the Killer Whale's sonar, respectively. $R$ is the slant range between the prey and the Killer Whale, $X$ is the horizontal range, and $\theta$ is the angle between the slant and horizontal range [9]. The angle $\theta$ can be determined by the equation.

$$
\theta=\sin ^{-1}\left(\frac{d_{F}-d_{o}}{R}\right)=\tan ^{-1}\left(\frac{d_{F}-d_{o}}{x}\right)
$$

Every search agent need a velocity to generate a movement in order to find a best solution location, in this algorithm, revers as a mathematical model for velocity movement.

$$
\left\{\begin{array}{l}
\overrightarrow{v_{l}} \leftarrow \overrightarrow{x_{l}}+\vec{U}\left(0, \emptyset_{1}\right) \otimes\left(\overrightarrow{p_{l}}-\overrightarrow{x_{l}}\right)+\vec{U}\left(0, \emptyset_{2}\right) \otimes\left(\overrightarrow{p_{g}}-\overrightarrow{x_{l}}\right) \\
\overrightarrow{v_{l}} \leftarrow \overrightarrow{x_{l}}+\overrightarrow{v_{l}}
\end{array}\right.
$$

\section{METHODS}

A four stroke gasoline engine (Husaberg FE450) was modelled by Ricardo Wave software. There are seven design parameters that used to simulate the operating condition of the engine. Detailed of each parameter correspond to each ranges are tabulated in Table-1.

Table-1. Design variables

\begin{tabular}{|l|c|}
\hline \multicolumn{1}{|c|}{ Design Variables } & Ranges \\
\hline RPM & {$[1000,6000]$} \\
\hline Air Fuel Ratio & {$[13,16]$} \\
\hline Mass fuel flow (kg/hr) & {$[0.5,6.3]$} \\
\hline Intake Air Temperature (K) & {$[293,297]$} \\
\hline Pressure Intake (bar) & {$[0.8,0.99]$} \\
\hline Combustion Start (degree) & {$[-10-26]$} \\
\hline Throttle valve angle (degree) & {$[10,90]$} \\
\hline
\end{tabular}

Ricardo Wave software is utilized to simulate the input-output of ANN training and validation data set.
The amount of data are 650 data set. 500 data are selected as training data set and 150 data as validation data set. The ANN architecture consist three layers i.e. input layer, hidden layer and output layer, as shown in Figure-1

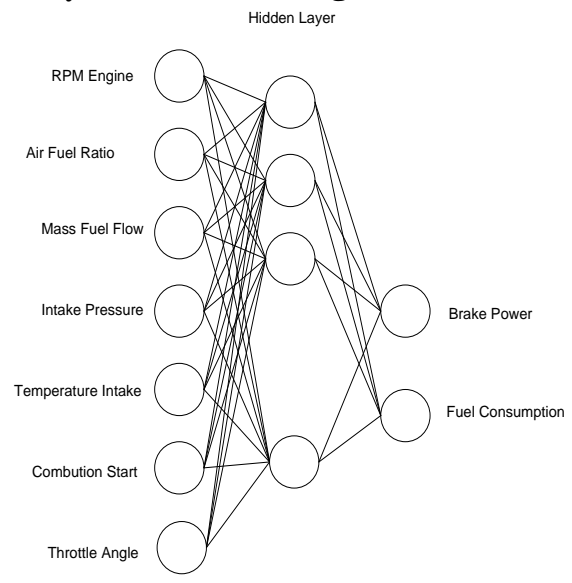

Figure-1 ANN Architecture with three layers

The formula inside the ANN model with activation function is expressed as follows:

$$
\begin{aligned}
& \mathrm{NET}_{\mathrm{i}}=\sum_{j=1}^{n} w_{i j} X_{j}+w_{b i} \\
& \mathrm{~F}\left(N E T_{i}\right)=\frac{1}{1+e^{-N E T_{i}}}
\end{aligned}
$$

where NET is output of the layer, $\mathrm{w}_{\mathrm{ij}}$ is the weights of the connection between $i_{\text {th }}$ and $j_{\text {th }} . X_{\mathrm{j}}$ is the output of the $j_{\text {th }}$ processing element. $\mathrm{w}_{\mathrm{bi}}$ is the weights of the biases between layers. Input and output values are normalized between 0 and 1.

Levenberg-marquardt algorithm is used to optimize the structure of ANN by determine number of neuron in a single hidden layer during training stage. Root Mean Square Error (RMSE) is utilized to indicate the accuracy of model during training and validation stages. RMSE can be expressed in equation (3).

$$
R M S E=\left(\left(\frac{1}{p}\right) \sum_{j}\left|t_{j}-o_{j}\right|^{2}\right)^{1 / 2}
$$

where $t$ is the target value, $o$ the output and $p$ the number of data.

Successively, Killer Whale Algorithm is performed to solve optimization of brake power and brake specific fuel consumption. The optimization scenario was divided into five different scenarios. This method is used to fulfill the possibility of gasoline engine operation. The constraints of the scenario are tabulated in Table-2. The parameter setting of Killer Whale Algorithm is shown in Table-3 
Table-3 Killer Whale Algorithm Properties

\begin{tabular}{|l|c|}
\hline \multicolumn{1}{|c|}{ Design Variables } & Scope \\
\hline Max Iteration & 200 \\
\hline Initial velocity & 0 \\
\hline Whale population & 90 \\
\hline
\end{tabular}

\section{RESULT AND DISCUSSION}

In this study, brake power and specific fuel consumption values were estimated by means of artificial neural network. The learning algorithm LevenbergMarquardt were utilized to determine the optimal learning algorithm. At the same time, a single hidden layer was established from 2 neurons to 100 neurons to determine the optimum of the number of hidden layer neuron. The result of this method is shown in Figure-2.

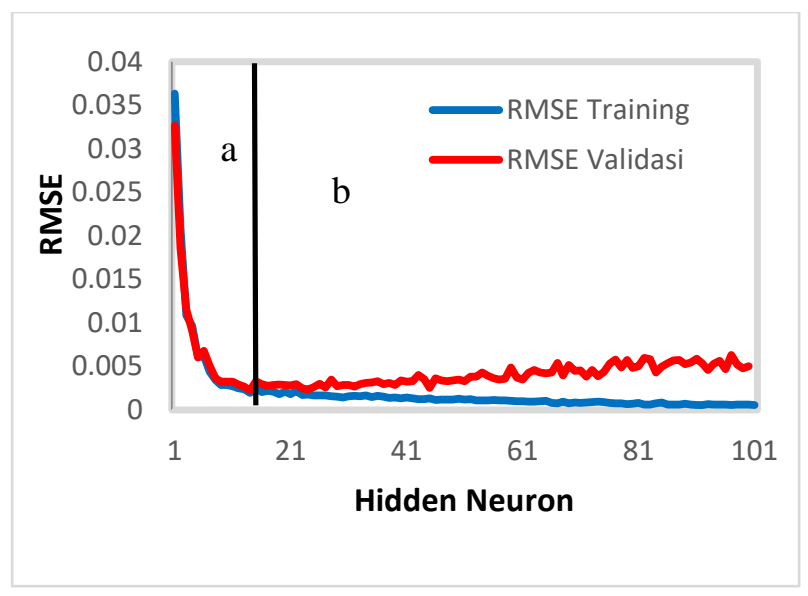

Figure-2 RMSE value for hidden neruons 2 to 100

A region is called an underlearning area where the model cannot predict the value of output well because of the small amount of training while the area $\mathrm{B}$ is called overlearning, because too much training the model cannot recognize data other than training data. in order for the model to recognize the data in general, the hidden neurons are selected between region $\mathrm{A}$ and region $\mathrm{B}$

The optimization is purpose to obtain the optimum objective function. The objective function of this study consist of two types i.e. maximize brake power and minimize fuel consumption. The results of the optimization are shown in Figure-3 and Figure-4.

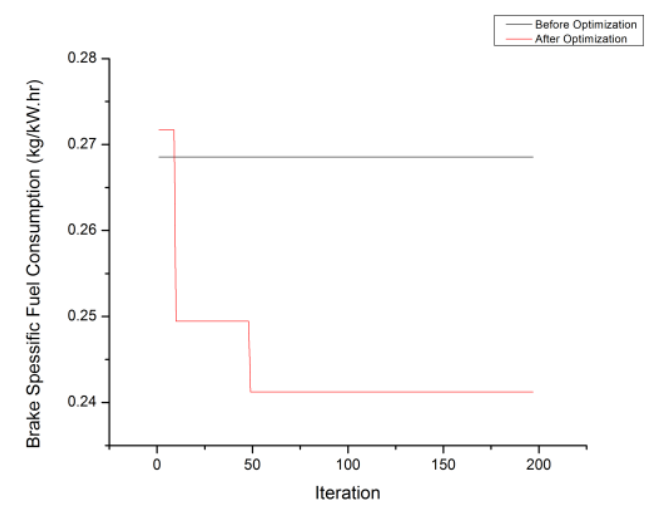

Figure-3 Optimization result of BSFC @ rpm 3000-4000

The results of optimization show that the minimum BSFC is $0.241 \mathrm{~kg} / \mathrm{kWh}$ compared to existing design is $0.268 \mathrm{~kg} / \mathrm{kWh}$, hence, the fuel consumption is decreased to $10.17 \%$.

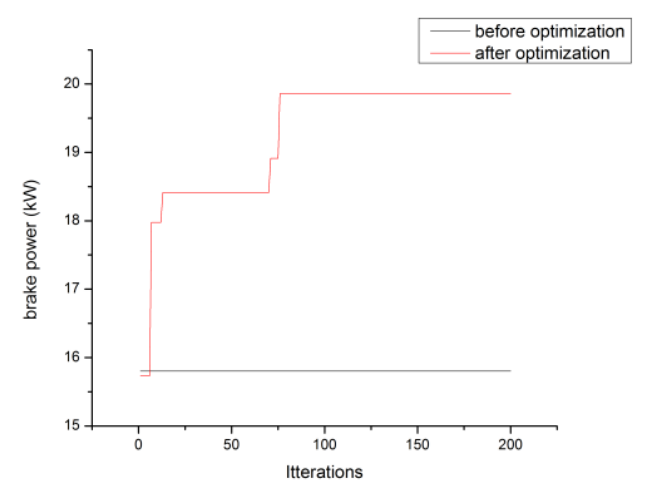

Figure-4 Brake Power Optimization @ rpm 3000-4000

In Figure 4 shows the optimization with objective function of brake power. Optimization is done at rpm 3000-4000 with a maximum objective function of $19.85865417 \mathrm{~kW}$. Brake power value before optimized is $31.22 \mathrm{~kW}$.hr. As a result of this brake power increased by $31.2 \%$.

\section{Conclusion}

In this paper, the lowest fuel consumption is $0.241 \mathrm{~kg} / \mathrm{kW} . \mathrm{hr}$ with design variables RPM, AFR, Mass Fuel Flow, pressure Intake, temperature intake, combustion start, throttle angle respectively are $3272,15.5,3.2 \mathrm{~kg} / \mathrm{hr}, 0.98 \mathrm{bar}, 295.92 \mathrm{~K}$, $15^{\circ}, 55^{\circ}$ with a percentage decrease after optimization is $10.71 \%$ at rpm $3000-4000$. The maximum power that can be generated is $19.85 \mathrm{~kW}$ with design variables RPM, AFR, Mass Fuel Flow, pressure Intake, temperature intake, combustion start, throttle angle respectively are 5350, 14.8, $6.3 \mathrm{~kg} / \mathrm{hr}, 0.98$ bar, $291.76 \mathrm{~K},-26.3^{\circ}, 80^{\circ}$ and percentage increase after Optimization is $31.2 \%$ at rpm $3000-4000$ 


\section{References}

[1] P. A. Shinde, "Research and Optimization of Intae Restrictor for Formula SAE Car Engine," International Journal of Scientific and Research Publication, vol. 4, no. 4, p. 1, 2014.

[2] M. H. Ismail, "Artificial neural network modelling of engine out responses for a light duty diesel engine fuelled with biodiesel blends," Applied energy, vol. 92, pp. 773-777, 2012.

[3] Y. Cay, "Prediction of a gasoline engine performance with artificial neural network," FUEL, vol. 111, pp. 325-331, 2012.

[4] M. Canacki, A. N. Ozsezen, E. Arcaklioglu and A. Erdil, "Prediction of performance and exhaust emmisions of a diesel engine fueled with biodiesel produced from waste frying palm," Expert system with aplication, vol. 36, pp. 9269-9280, 2009.

[5] B. Ghobadian and H.Rahimi, "Diesel engine performance and exhaust emission alysis using waste cooking biodiesel fuel with an artificial neural network," Renewable Energy, vol. 34, pp. 976-982, 2009.

[6] H. Langouet, L. Mectivier, D. Sinoquet and Q.-H. Tran, "Engine calibration: multi-objective constrained optimization of engine maps," Optimization and Engineering, vol. 12, no. 3, pp. 407-424, 2011.

[7] J. M. Alonso, F. Alvarruiz, J. M. Desantes, V. h. Leonor Hernandez and G. Molto, "Combining neural network and genetics algorithms to predict and reduce diesel engine emmisions," IEEE Transactions on Evolutionary Computation, vol. 11, pp. 46-54, 2007.

[8] L. Fausett, Fundamentals of Neural Network Architecture, Algorithm, and Application, New Jersey: Prentice Hall, 1994.

[9] T. R. Biyanto, M. N. Syamsul, H. Fibrianto, N. Affandy, K. S. Gunawan, A. H. Rahman, J. A. D. Pratama and A. I. Abdillah, "Optimization of Energy Efficiency and Conservation in Green Building Design Using Duelist, Killer Whale and Rain Water Algorithms," in press, 2017. 